The Journal of Animal \& Plant Sciences, 30(3): 2020, Page: 713-722

ISSN (print): 1018-7081; ISSN (online): 2309-8694

\title{
GENUS XANTHOPIMPLA SAUSSURE, 1892 (ICHNEUMONIDAE: PIMPLINAE) FROM POTHWAR REGION (PUNJAB) OF PAKISTAN
}

\author{
S. Ahmed ${ }^{1}$, I. Bodlah ${ }^{1 *}$ M. F. Nasir ${ }^{1}$ and M. S. Nadeem ${ }^{2}$ \\ ${ }^{1}$ Insect Biodiversity and Conservation Group, Department of Entomology, Pir Mehr Ali Shah Arid Agriculture \\ University, Rawalpindi, Pakistan; ${ }^{2}$ Department of Zoology, Faculty of Sciences, Pir Mehr Ali Shah Arid Agriculture \\ University, Rawalpindi, Pakistan. \\ *Corresponding author's email: imranbodlah@gmail.com
}

\begin{abstract}
Members of Genus Xanthopimpla Saussure, 1892 (Hymenoptera: Ichneumonidae: Pimplinae) are reported as important bio-control agents of different insect pests of various crops. Four species were recorded from Pothwar region with Xanthopimpla reicherti Krieger, 1914 as new record for Pakistan. New distributional records for Xanthopimpla punctata Fabricius, 1781, Xanthopimpla stremmator Thunberg 1822, and Xanthopimpla flavolineata Cameron, 1907 in Pothwar have been added. Comparison of recorded species with closely related species, distribution ranges, and remarks on their host are given. An identification key of recorded species, as well as brief description of each species has been provided, and supplemented with illustrations using microphotography from the external morphological details. Arc GIS software was used for spatial distribution of identified species. Results of these studies including illustrations may be helpful for field workers for identification and researchers to formulate IPM strategies against various insect pests of crops in different districts of Pothwar region of Pakistan.
\end{abstract}

Keywords: Ichneumonidae, Pimplinae, Xanthopimpla, Pothwar, New country record. https://doi.org/10.36899/JAPS.2020.3.0084 Published online March 25, 2020

\section{INTRODUCTION}

Pimplinae is the most studied group of family Ichneumonidae as parasitoids of important Lepidopterous pest of agriculture crops (Brooks and Wahl, 1987; Matsumoto and Konishi, 2007).Genus Xanthopimpla was erected for the first time by Saussure in 1892. Members of genus Xanthopimpla Saussure, 1892 are small to large in size and classified under tribe Ephialtini of subfamily Pimplinae (Gupta, 1987; Gauld et al., 2002). Members of this genus are reported as endoparasitoid of Lepidopterous pest and their utilization in controlling pest is documented in various regions of the world (Townes and Chiu (1970); Gauld (1984); Hailemichael et al.(1994); Gitau et al.(2007); Dung et al. (2011) etc.

Xanthopimpla species can be recognized by yellow body with stout legs and variables spots or black bands on abdominal tergites (David et al., 2013).Bidentate mandibles and lower teeth twisted are two characters which differentiate this genus from others (Gauld, 1984). A lot of faunal studies of this genus from different regions of the world include Thunberg (1822); Saussure (1892) and Krieger (1914) from Palearctic region; Tosquinet (1896) and Seyrig (1932) from Afrotropical region; Townes 1969 and Gómez et al. $(2009 ; 2014)$ from Neotropical regions and Townes \& Chiu (1970), Gupta (1987), Pham et al. (2011) from oriental regions etc.
A total of 261species of Xanthopimpla have been identified from all over of the world with greater number of 149 species from oriental region and less number in Afrotropical and Neotropical region (Yu et al., 2005; Pham, 2013; Townes and Chiu, 1970).Townes and Chiu (1970) described the genus Xanthopimpla from Indo-Australian area with 22 species groups to classify the large number of species. Abundance in different habitat depicts its vital role as natural controlling agent, which manifolds its importance especially in indo Australian region where they outnumbered than other regions (Gupta, 1987).

A limited work (Townes et al., 1961; Gupta, 1987; Irshad and Khan, 2005) has been done on this genus in Pakistan as compared to records of many species of this genus in neighboring countries like India 41 species and China 46 species (Akhtar et al. 2010).

During our surveys for the exploration of Ichneumonidae from Pothwar region, four species of Genus Xanthopimpla were collected from various areas of Pothwar region of Pakistan.

\section{MATERIALS AND METHODS}

Study was conducted in Pothwar region including Islamabad Capital Territory during 2017-18. Sweep net was used for collection of specimens from agro-ecosystems, forests and rangelands. 
Different areas of districts Rawalpindi, Jhelum, Chakwal, Attock and Islamabad Capital Territory were extensively surveyed for specimen collection. Specimens were killed in glass bottle containing Potassium cyanide. Pinning of specimens was done and preserved in insect preservation Boxes. Specimens were observed using Labomed microscope (CZS6).Townes (1969) and Eady (1968) were followed for morphological and microsculpture terminologies. Taxonomic literature by Morley (1913); Townes (1971); Gupta (1987); Townes and Chiu (1970) was used for identification of species.

Microphotography of main identification characters was done with the help of Amscope 18 megapixel camera attached with LEICA MS 5 microscope. Microphotographs were stacked with the help of Helicon focus 6. Further processing and cleaning of microphotographs was done with the help of Adobe Photoshop CS6. Identified specimens were deposited in Department of Entomology, PMAS-Arid Agriculture University Rawalpindi. Abbreviations TBL and FWL represent Total body length and Fore wing length in micrometers.

\section{RESULTS}

Four species of genus Xanthopimpla under subfamily Pimplinae were collected and identified Xanthopimpla reicherti Krieger, 1914 is recorded as new record from Pakistan. Xanthopimpla punctata, Xanthopimpla stremmator, and Xanthopimpla flavelinate are reported as new additions from Pothwar region of Pakistan. With reference to division of Townes and Chiu, 1970 four species group Punctata, Stemmator, Citrina and newly reported specie fall under Brachycentra group in current study.

\section{Genus Xanthopimpla Saussure, 1892}

Xanthopimpla Saussure 1892: P1.13. Type specimen: Xanthopimpla hova Saussure; Ashmead 1900:56

Diagnosis: Body small to large sized, head with emarginated eyes, complete occieptal carinae and antennae with short flagellomeres anteriorly. Clypeus apically truncate or concave, transverse suture separates lower and upper clypeus, bidentate mandibles narrowed strongly and lower mandibles invisible anteriorly as twisted at $90^{\circ}$. Noutli present on mesoscutum .Epomia and pronotum short and mesopleuron characterized with epicnemial carina and postpectal carina and mesepisternum present centrally. Carination present on propodeum. Spatulate bristles present instead of basal lobe in tarsal claws of female. Commonly areolated wing, thick stout body bright yellow in colour with black bands or spot. Ovipositor usually lightly exceeding last abdominal segment and always greater in length than hind tibia (Townes \& Chiu, 1970, Gauld, 1984).

\section{Key to species of genus Xanthopimpla in Pothwar} region of Pakistan:

1. Whole body yellow except black oceller area of head. Areola of propodeum receiving costula behind its center (Fig. 5A). Stigma of forewing testaceous............ flavolineata

-. $\quad$ Body with black spots or bands on dorsal side as well as on leg parts. Areola of propodeum receiving costula near its center or at its apex. Stigma of forewing other than testaceous...............2

2. Black bands on tergite 1, 3 and 7 (Fig. 3E), occipital area of head yellow. Ovipositor 0.4 $0.6 x$ of hind tibia............... . reicherti

-. Black spot present on mesoscutum, propodeum and on abdominal tergites . Occipital area of head yellow or with spots. Ovipositor equal or more $1 \mathrm{x}$ of hind tibia....................... 3

3. Areola enclosed by carina and 0.4 to 0.5 as long as wide. Tergites 2 and 4 usually immaculate (Fig. 2E). Ovipositor 1.7 to $1.9 \mathrm{x}$ of hind tibia length. Hind tibia black at base.................... .punctata

-. $\quad$ Areola enclosed by carina and1.0-1.2 x as long and wide. Tergite 2 and 4 with two black spots (Fig. 4E). Ovipositor 1 to $1.2 \mathrm{x}$ of hind tibial length. Hind tibia entirely immaculate............ stremmator

Xanthopimpla flavolineata Cameron, 1907 Figs. (1A-F, 5A, 6)

Xanthopimpla flavolineata Cameron. 1907. Tijdschr. V. Ent., 50: 48. F, key, des. Type; F, Indonesia: West Irian: Merauke (Amsterdam)

Xanthopimpla emaculata Szepligeti, 1908

Xanthopimpla immaculata Morley, 1913.

Xanthopimpla hyalotila Krieger, 1914

Xanthopimpla xanthostigma Girault. 1925

Xanthopimpla xara Cheesman, 1936

Melopiu ssesamiae Rao, 1935

Xanthopimpla Jlavolineata Townes \& Chiu, 1970

Material Examined: Pakistan; Punjab, Attock, Hassanabdal Por Miana (3349'39.49"N, 7247'14.42"E

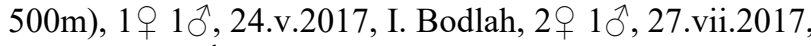
S. Ahmed, 1§, 02.xi.2018, S. Ahmed, Jehlum Domile $\left(33^{\circ} 00^{\prime} 33.16^{\prime \prime} \mathrm{N}, \quad 73^{\circ} 21^{\prime} 26.26^{\prime \prime} \mathrm{E} 325 \mathrm{~m}\right) \quad 1$ 웅, 12.v.2018, S. Ahmed, Chakwal, Kallar Kahar $\left(32^{\circ} 47^{\prime} 44.25^{\prime \prime} \mathrm{N} \quad 72^{\circ} 43^{\prime} 46.69^{\prime \prime} \mathrm{E}, \quad 721 \mathrm{~m}\right) \quad 2$ 웅․ 23.vi.2018, S. Ahmed.

Diagnosis: Stigma of forewing testaceous, areola on propodeum receiving costulae behind the center and longer than wide; evenly convex scutellum, ovipositor is $0.6 \mathrm{x}$ of hind tibia. Devoid of any black band or spot on the body except black ocellar area and apically black claws. 
Description: Female TBL.6.5-7.5mm. FWL.5$6 \mathrm{~mm}$.Antennae with 43-46 flagellomeres. First antennal segment is $2 \mathrm{x}$ of 2 nd segment. Greater number of flagellomeres in male antenna. Weakly convex clypeus, convergent eyes with flat punctate face (Fig.1D).Ocellar ocular distance equal to diameter of lateral ocellus. Malar space $0.3 \mathrm{x}$ of basal width of mandibles. Occipital complete and yellow in colour without band or black mark. Areola complete surrounded by carina and receiving costula behind the center. Basal area confluent with areola (Fig. 1F).). Apical transverse carina completes and separated the areola and secondary lateral area from petiolar area (Fig. 5A). Mesopleuron characterized by Epicenimal carina (Fig. 1C). Wings with areolet and $2 \mathrm{~m}-\mathrm{cu}$ vein arises from lower center of the areolet. Nervulus opposite with basal vein (Fig. 1B). Apical bristles 5-6 on hind tibia. First tergum with median as well as lateral dorsal carina. First tergite $0.25 \mathrm{x}$ of 2nd tergite (Fig.1E). Ovipositor short and straight, characterized by tooth on lower valve (Fig. 1A).

Colour pattern: Usually whole body is immaculate with yellowish brown rhombic areas on tergites. Antennal segment brownish from base to dark brown at apex.

General Distribution: Pakistan, Bangladesh, India, China, Sri Lanka, Nepal, Vietnam, Indonesia, Malaysia, Japan, Taiwan, Australia, Philippines (Yu et al. 2005).

Remarks: This species belongs to the Citrina species group (Townes and Chiu, 1970). Xanthopimpla modestsis closely related with Xanthopimpla faveolineata and belongs to same species group however vertex and ocellar area black in modesta and yellow in flaveolineata (Pham et al., 2011).Cnaphalocrocis medinalis (Noctuidae) (rice leaf roller), Pelopidas mathias (Hesperiidae) (lesser millet skipper) and Lamprosema indica (Pyralidae) are reported lepidopterous host of this species (Townes et al., 1961; Khuat \& Pham 2007).During this study specimens were collected from maize field where lepidopterous insects were dominant pests.

Xanthopimpla punctata Fabricius, 1781 Figs. (2A-F, 5B, 6)

Ichneumon punctatus Fabricius 1781. Species Insectorum, 1: 437. (M) des. Type: M, India:

"Coromandel" (Kiel, on deposit in Copenhagen).

Pimpia transversalis Vollenhoven, 1879

Xanthopimpla ruficornis Krieger, 1899

Zanthopimpla appendiculata Cameron, 1902

Xanthopimpla brunneciornis Cameron, 1903

Xanthopimpla kandyensis Cameron, 1905

Xanthopimpla lissonola Cameron, 1906

Neopimpla punctata Kvroiwa, 1908

Xanthopimpla punctata Morley, 1913
Diagnosis: Areola complete enclosed by carina $0.4-0.5 \mathrm{x}$ as long as wide. Scutellum convex. Tergites 2, 4 and 6 are immaculate while rest of tergites always bimaculated. Ovipositor about 1.7-1.9x of hind tibia length.

Material Examined: Pakistan; Punjab, Attock, Hassanabdal Por Miana (3349'39.49"N, 7247'14.42"E, 500m), $1 q 1 \overbrace{}^{\lambda}, 28 . x .2017$, S. Ahmed, $1+2 \overbrace{}^{\Uparrow}, 02.1 x .2018$, I. Boblah, Hazro (3354'40.54" N, 72²9'56.69" E, 316 m) , $291 \hat{\jmath}, 02 . x i .2018$, S. Ahmed, Islamabad Capital Territory kachnar Park (33 $40^{\prime} 32.99^{\prime \prime} \mathrm{N}, 7^{\circ} 04^{\prime} 39.15^{\prime \prime} \mathrm{E}$, $522 \mathrm{~m}), 2 \bigcirc$ 1 $\widehat{\delta}, 14 . x .2017$, S. Ahmed, Rawalpindi, Murree Numbehr Mall (3247'44.25" N, 7243'46.69" E,

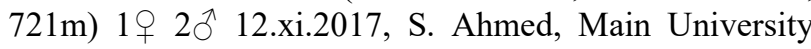
Campus UAAR $\left(33^{\circ} 38^{\prime} 56.38^{\prime \prime} \mathrm{N}, 73^{\circ} 04^{\prime} 54.36^{\prime \prime E}, 501 \mathrm{~m}\right)$, 1 이 10̄, 20.ix.2018, I. Bodlah. Gujar Khan

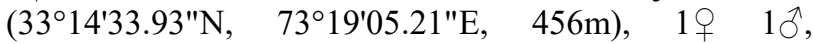
15.ix.2018, S. Ahmed, Taxila, Ghazi $\left(33^{\circ} 44^{\prime} 01.57^{\prime \prime} \mathrm{N}\right.$, 7244'07.29"E, 477m) 2 ㅇ 2厅, 28.x.2017, S. Ahmed.

Description: Female TBL.10-12mm. FWL.7mm-9mm. Antennae with 35-38 flagellomeres First antennal segment $1.5 \mathrm{x}$ of $2^{\text {nd }}$ segment. Head characterized by weakly convex clypeus; flat face with close punctures; eyes parallel (Fig. 2D). Ocellar ocular distance $1.25 \mathrm{x}$ diameter of lateral ocellus. Malar space $0.3 \mathrm{x}$ of basal width of mandibles Short Noutli on mesoscutum not reaching the tegula. Occipital complete and yellow in colour without band or black mark (Fig .2C). Pronotum with carination and complete areola present wider than long (Fig. 2F). Posterior transverse carina of propodeum complete while median longitudinal carina attached transverse carina of areola before center on both sides. First lateral area on propodeum $2 \mathrm{x}$ long and wide than $2^{\text {nd }}$ lateral area on propodeum. (Fig. 5B) Forewing areolated with $2 \mathrm{~m}$-cu vein with 2 bullae, nervulus opposite with basal vein (Fig. 2B). First tergites $1.25 \mathrm{x}$ wide as long with median dorsal carina. $2^{\text {nd }}$ tergite without punctuation and $3^{\text {rd }}$ to $6^{\text {th }}$ distinctly punctate (Fig. 2E). Hind tibia with 6-8 apical bristles .Ovipositor long and straight usually $1.7-1.9 \mathrm{x}$ of hind tibia length and characterized by tooth on upper valve (Fig. 2A).

Colour pattern: Bright lemon yellow body, mesoscutum with three black spots, propodeum bimaculated in first lateral area, tergites 2, 4 and 6 are immaculate while rest of tergites bimaculated. Basal part of hind tibia black.

General Distribution: Afghanistan, Bangladesh, Pakistan, Nepal, India, Sri Lanka, Vietnam, Russia, China, Taiwan, , Myanmar, Thailand, Malaysia, Singapore, Indonesia, Philippines, Japan, Australia (Yu et al. 2005).

Remarks: This species belongs to the $X$.punctata species group (Townes \& Chiu, 1970). Xanthopimpla predator (The Reigna group) is similar to Xanthopimpla puntata in appearance and characteristics. However, face 
with sublateral vertical ridges, short ovipositor, subpyramedial scutellum and presence of spot on hind trocachter differentiate from punctata (Morely (1913); Townes and Chiu (1970); Pham et al. (2011). Sylepta derogata (pyralidae), cotton leaf roller (Ghani, 1960), Chilo sacchariphagus, C. suppressalis (Jonathan, 1999) Chilopartellus, corn borer (Butani, 1972) Cnaphalocrocis medinalis (Pyralidae), the rice leafroller, Parnara guttata (Hesperidae), Naranga aenescens (Noctuidae) (Khuatand Pham, 2007) are reported host of this species. During this study the specimens of this species were collected from maize, sorghum and sugarcane crop having host as pest of these crops.

Xanthopimpla reicherti Krieger, 1914 Figs. (3A-F, 5C, 6)

Xanthopimpla reicherti Krieger, 1914.Arch. f.

Naturgesch. (A) 80(6): 40, 89.

Lectotype: + , Myanmar: Pekon on Loikaw River, Karenni State (ZMHB).

Material Examined: Pakistan Punjab Rawalpindi, Murree, Numbehr Mall (32॰47'44.25"N, 7243'46.69"E,

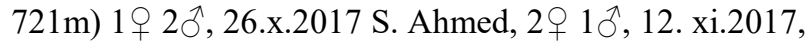
I. Bodlah, $2 \bigcirc 1 \hat{\jmath}$, 16.ix.2018, S. Ahmed.

Diagnosis: Black bands on tergite 1, 3 and 7, two black spots on $4,5^{\text {th }}$ tergites. 5-6 preapical bristles on hind tibia; $2^{\text {nd }}$ tergite least punctate whereas tergites 3 to 5 densely punctated. Ovipositor $0.4-0.6 x$ of hind tibia.

Description: Female TBL. 8-10mm. FWL.6-7mm. Antennae brownish with 33-35 flagellomeres. First antennal segment is $1.8 \mathrm{x}$ of $2^{\text {nd }}$ segment. Head characterized by weakly convex clypeus; flat face with close punctures; eyes parallel (Fig. 3D). Basal width of mandibles less than malar space. Ocellar ocular distance equal to diameter of lateral ocellus. Mesoscutum with short hairs and Noutli reaching up to tegula. Occipital complete and yellow in colour without band or black mark (Fig. 3C). Convex shaped scutellum with black spot in front on mesoscutum. Pronotum with carination and complete areola present more wider than long (Fig. 3F). Areola completely surrounded by carina and receiving costula near the center. Basal area confluent with areola. Posterior transverse carina of propodeum complete (Fig. 5C). First lateral area $2 \mathrm{x}$ of second lateral area of propodeum. Forewing areolated with $2 \mathrm{~m}-\mathrm{cu}$ vein with 2 bullae, nervulus opposite with basal vein (Fig.3B). First tergite 0.2 to $0.3 \mathrm{x}$ of $2^{\text {nd }}$ tergite and both least punctate whereas tergites 3 to 5 densely punctate (Fig. 3E). Ovipositor is slightly larger $0.4-0.6 \mathrm{x}$ hind tibia (Fig. 3A).

Colour pattern: Bright lemon yellow colour body mesoscutum with black band on basal part and black spot in front of scutellum, propodeum bimaculated in first lateral area, tergites 1, 3, 7 each with black band, tergites
4-5 each with two black spots. Basal part of hind tibia black in colour.

General Distribution: China, India, Myanmar, Thailand and Vietnam Pakistan (New Record) (Akhtar et al. 2010).

Remarks: This species belongs to The Brachycentra species group (Townes and Chiu, 1970). This species is a new record from Pakistan, collected from shrubs under forest at Murree. Two subspecies $X$. reicherti separata Townes \& Chiu reported from china only whereas and $X$. reicherti reicherti from China, India, Myanmar, Thailand, and Vietnam. Both subspecies differ in the shape of black marks on the mesoscutum and the first tergite (Pham et al., 2011).

\section{Xanthopimpla stremmator Thunberg, 1822 Figs. (4A-F, 5 D, 6)}

Ichneumon stemmator Thunberg, 1822. Mem. A cad. Imp. Sci. St. Petersburg, 8: 262. Key, des. Type: m, China (Uppsala)

Pimpla integrata Smith, 1860

Xanthopimpla thoracalis Krieger, 1899

Xanthopimpl amaculifrons Cameron, 1903

Xanthopimpla bimaculata Cameron, 1906

Xanthopimpla nursei Cameron, 1907

Xanthopimpla maculifrons Cameron, 1907

Xanthopimpla facialis Szepligeti1, 908

Xanthopimpla stemmator: Townes \& Chiu, 1970

Material Examined: Pakistan; Punjab, Attock, Dhoke Syeden (3331'41.77"N ,72³8'35.79"E, 472m), 1 ㅇ 10,29.x.2017, S. Ahmed ,Hassanabdal Por Miana (334' $\left.39.49^{\prime \prime} \mathrm{N}, \quad 72^{\circ} 47^{\prime} 14.42^{\prime \prime} \mathrm{E}, \quad 500 \mathrm{~m}\right), \quad 2$ ㅇ $1{ }^{\jmath}$, 24.iii.2017, S. Ahmed, 1 ㅇ 20̄, 29.iv.2017, I. Bodlah, 2 ㅇ

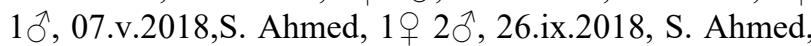

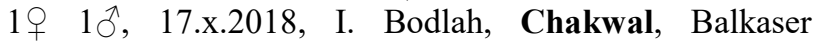
(3256'27.05"N, 72³9'30.61"E, 530m) 1 ㅇ 19.x.2017, S. Ahmed, Jehlum, Pind Dadan Kahan, Shakmeer, (32॰34'23.07"N, 7302'19.00"E,202m) 1ㅇ 2今,12.v.2018 ,S. Ahmed ,Rawalpindi, Bai $\left(33^{\circ} 50^{\prime} 22.79^{\prime \prime} \mathrm{N}\right.$ ,72॰39'42.44"E,415m), 2 우 10̄, 04.iii.2017,S. Ahmed, University Campus UAAR (333' $56.38^{\prime \prime} \mathrm{N}$,

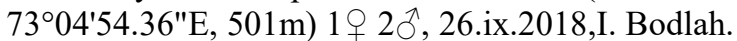

Diagnosis: Two black spots present on hind side of head; hind tibia with 8-10 preapical bristles; propodeum first lateral area and metasomal tergites bimaculated while tergite 6 immaculate. Ovipositor 1 to $1.2 \mathrm{x}$ of hind tibial length.

Description: Female: TBL.10-12mm. FWL.6-8mm. Antennae with 34-36 flagellomeres. First antennal segment is $2 \mathrm{x}$ of $2^{\text {nd }}$ antennal segment. Head characterized by weakly convex clypeus, flat face with sparse punctures, eyes parallel (Fig. 4D).Ocellar ocular distance equal to diameter of lateral ocellus. Malar space 
more or less equal to basal width of mandibles. Notauli on mesoscutum not reaching up to tegula. Occipital complete and yellow in colour with two black mark. Convex to conical shaped. Scutellum with black spot in front on mesoscutum (Fig 4F).Pronotum with carination and complete areola. Areola enclosed by carina and1.0$1.2 \mathrm{x}$ as long and wide. Anterior transverse carina absent from middle whereas Posterior transverse carina of propodeum complete (Fig. 5D). Forewing areolated with $2 \mathrm{~m}$-cu vein with 2 bullae, nervulus opposite with basal vein (Fig. 4B). First tergite more or less equal to $2^{\text {nd }}$ in length and first two tergites are sparsely punctate while rest are closely punctate (Fig .4E). Ovipositor shorter than half length of abdomen (Fig. 4A).

Colour pattern: Bright yellow colour body mesoscutum with two black spots, propodeum bimaculated in first lateral area, tergite 6 immaculate while rest of tergites bimaculated. Hind tibia entirely immaculate.
General Distribution: Pakistan, China, India, Sri Lanka, Laos, Thailand, Malaysia, Singapore, Indonesia, Philippines, Taiwan, Japan, Mauritius and South Africa (Yu et al., 2005).

Remarks: This species belongs to Stemmator species group (Townes \& Chiu, 1970). This species has wide host range of stem borers like Scirpophaga nivella, Scirpophaga incertulas,Sesamia inferens, Chilo suppressalis, Chilo zonellus, Chilo auricilia,Chilo partellus ,C. sacchariphagus and Eldana saccharina (Townes and Chiu (1970); CIBC (1973); Facknath(1989); Ganeshan (2000); Conlongand Goebel (2002); Ganeshanand Rajabalee (1997). Due to vast host range it is extensively investigated as a bio-control agent against lepidopterous stem borers (Pham et al., 2011).Specimens of this species were collected from the maize, sorghum and sugarcane crop infested by Lepidopterous pests.

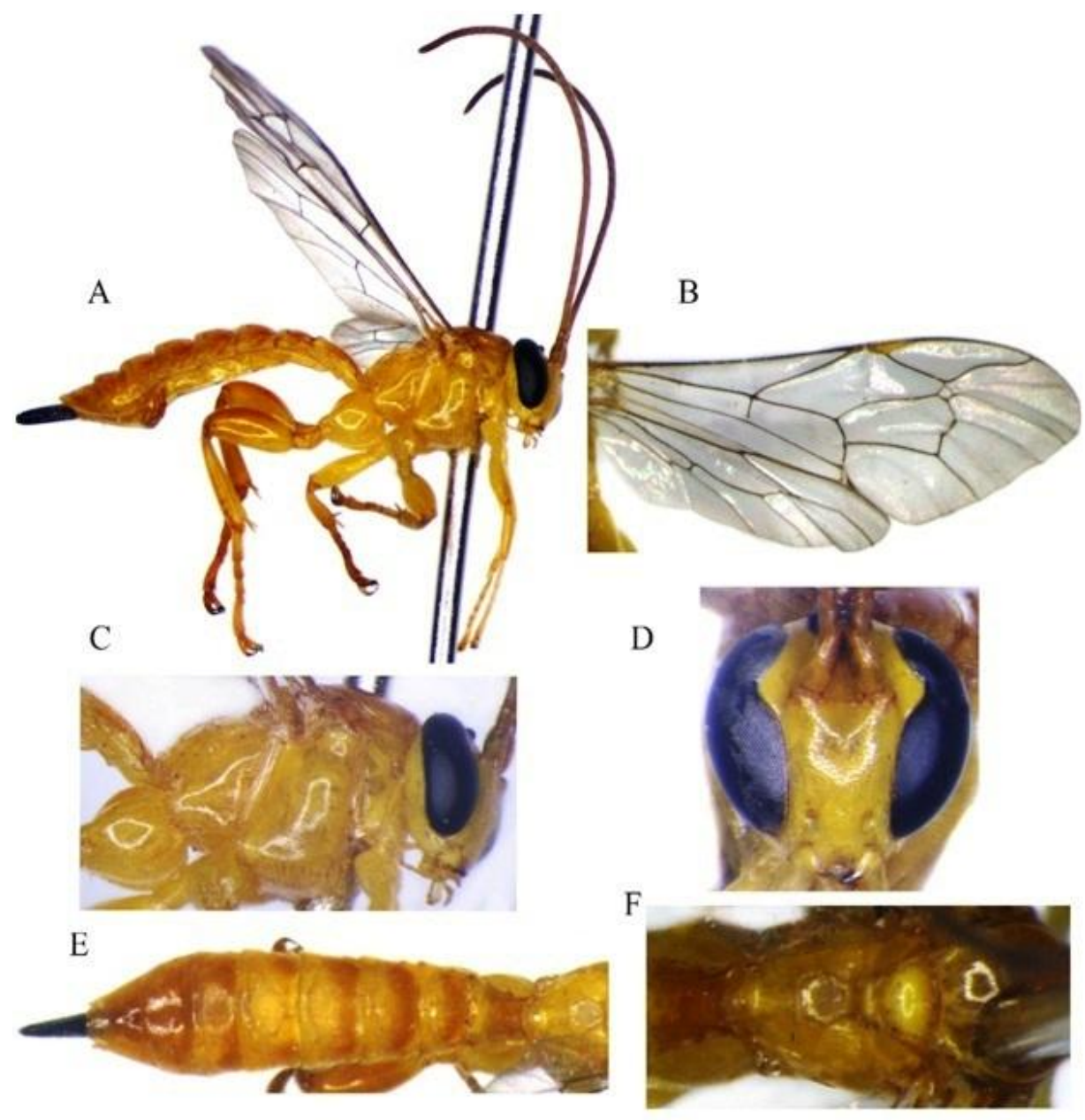

Figure 1. Xanthopimpla flavolineata (A- E): A. lateral view of body; B, fore wing; C, lateral view of mesosoma; D, frontal view of head; $E$, dorsal view of abdomen; $F$, dorsal view of scutellum and propodeum 


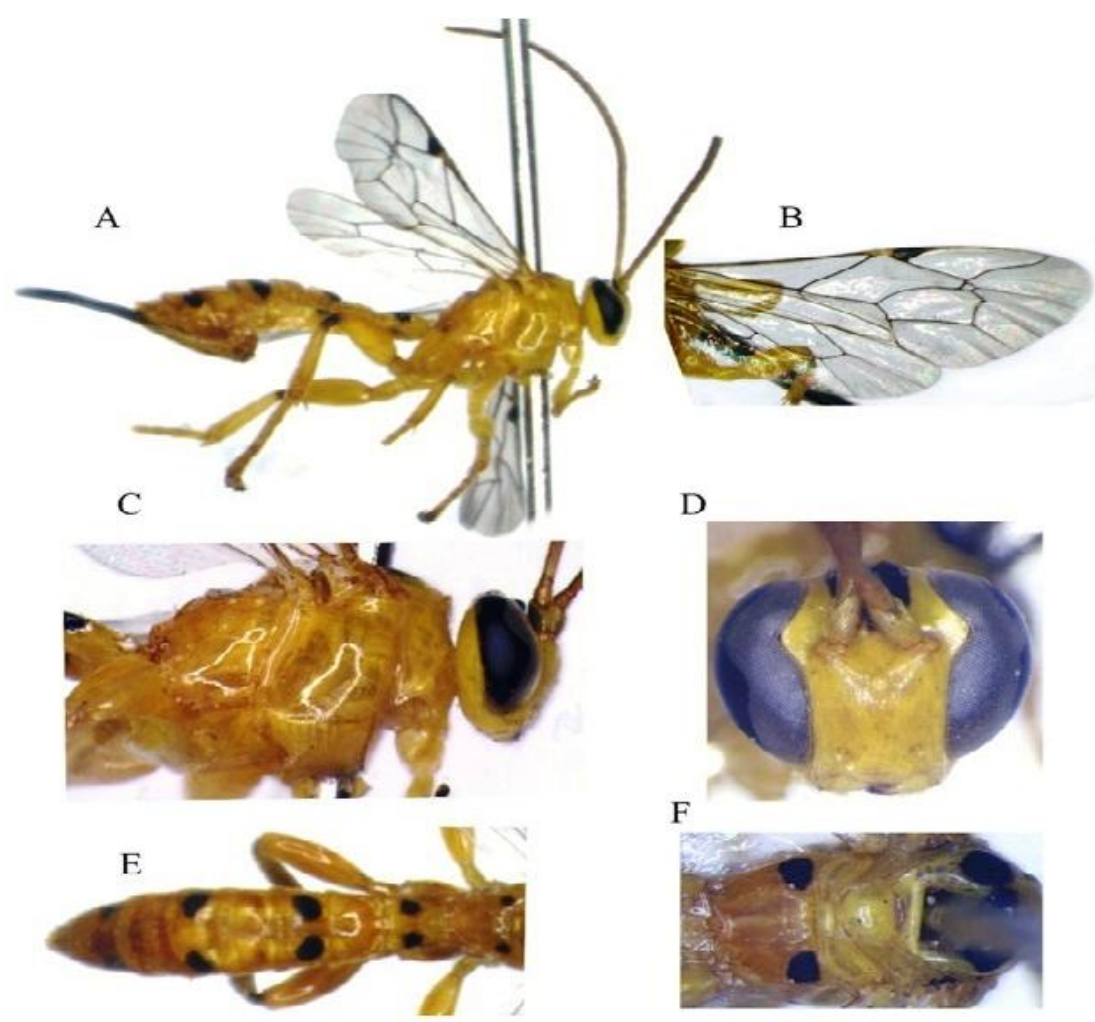

Figure 2. Xanthopimpla punctate (A-E): A. lateral view of body; B, fore wing; C, lateral view of mesosoma; D, frontal view of head; $E$, dorsal view of abdomen; $F$, dorsal view of scutellum and propodeum

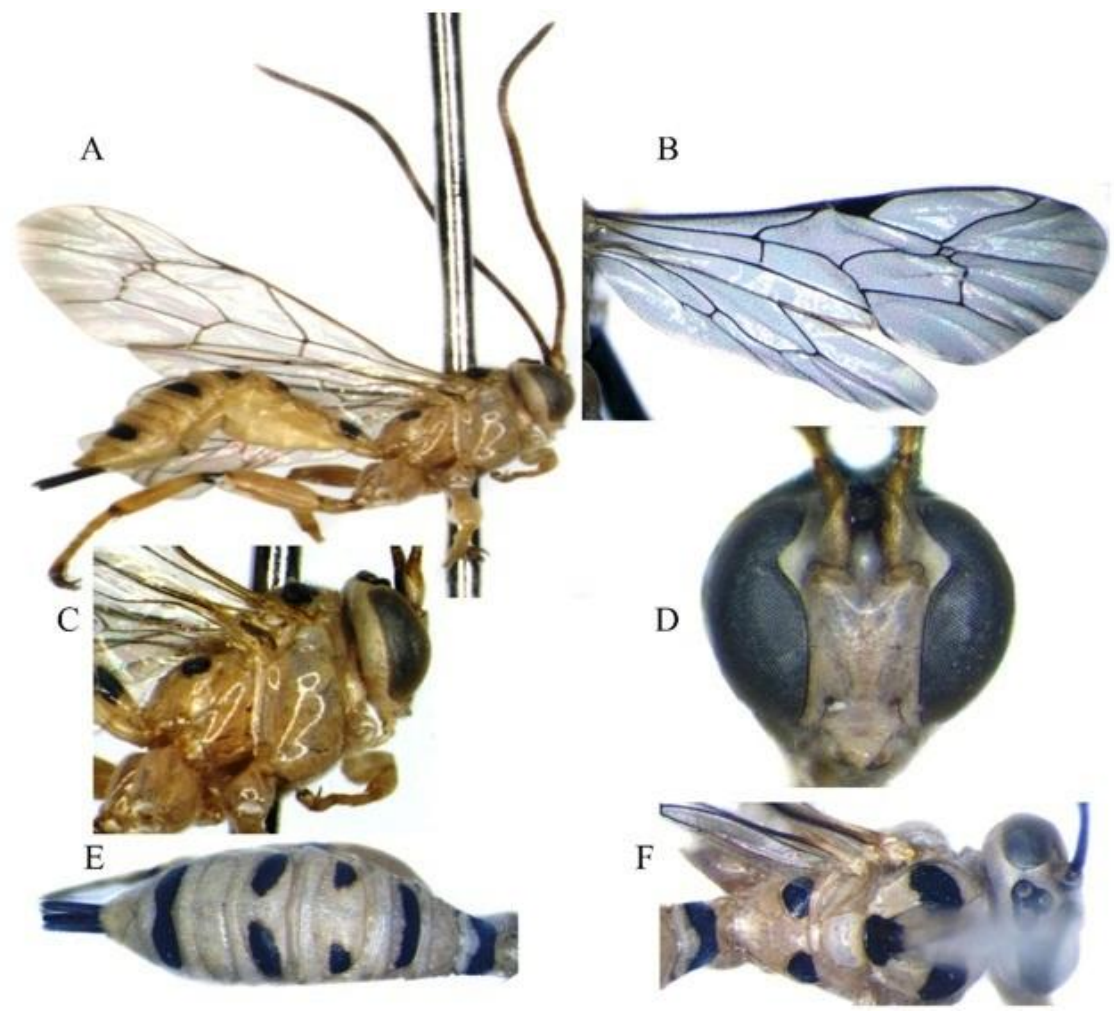

Figure 3. Xanthopimpla reicherti (A-E): A. lateral view of body; B, fore wing; C, lateral view of mesosoma; D, frontal view of head; $E$, dorsal view of abdomen; $F$, dorsal view of scutellum and propodeum 


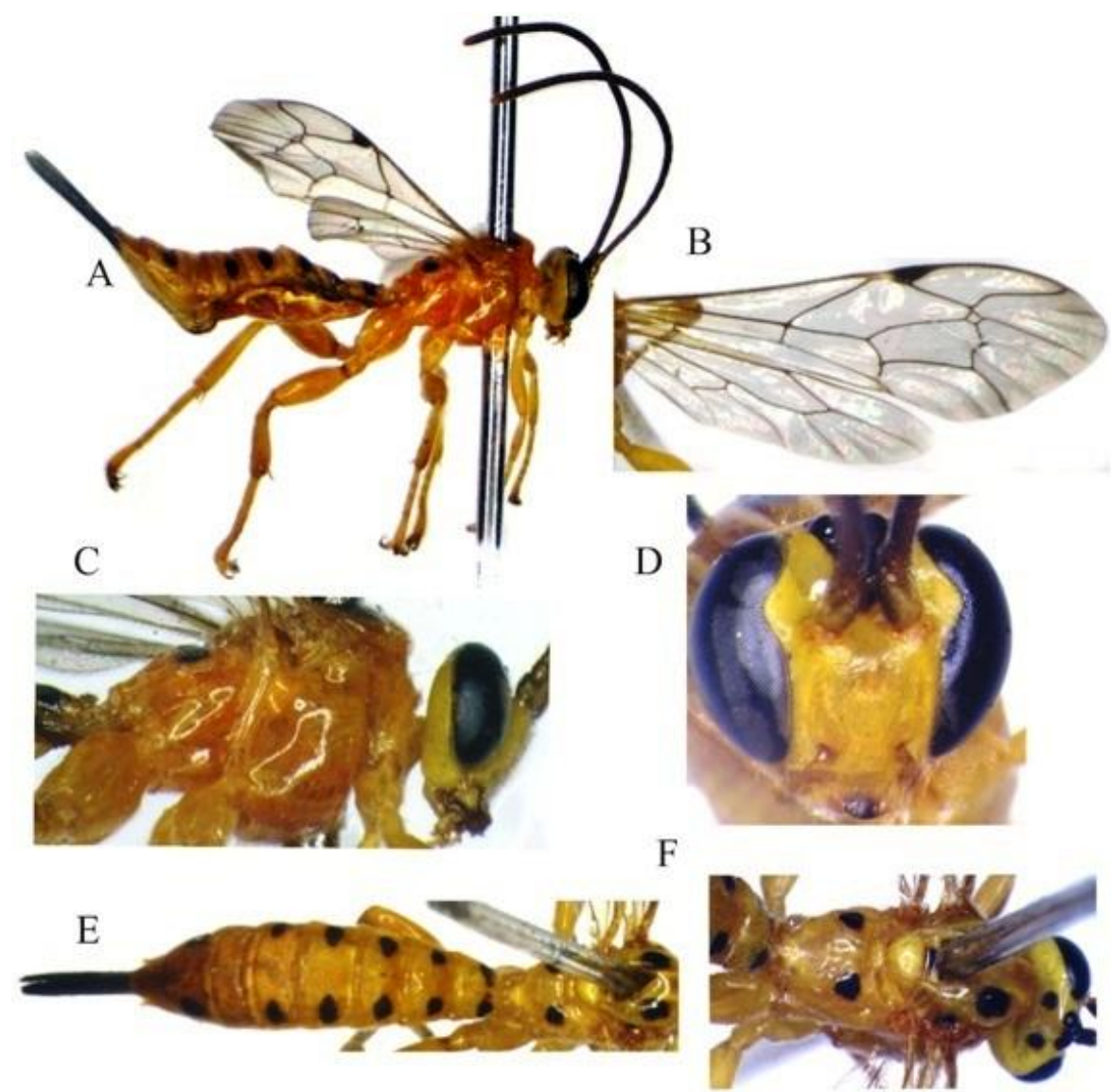

Figure 4. Xanthopimpla stremmator (A-E): A. lateral view of body; B, fore wing; C, lateral view of mesosoma; D, frontal view of head; E, dorsal view of abdomen; F, dorsal view of scutellum and propodeum.

A

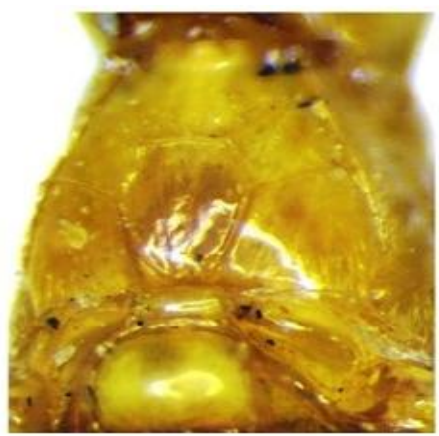

C

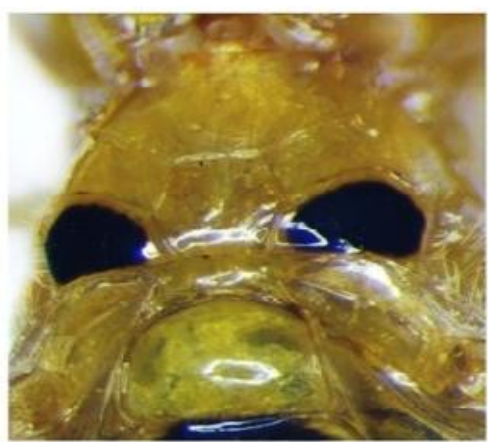

B

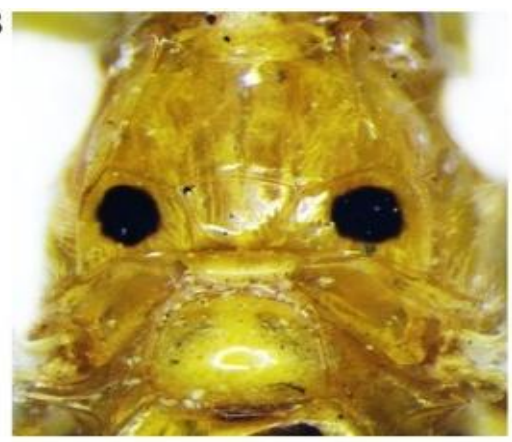

D

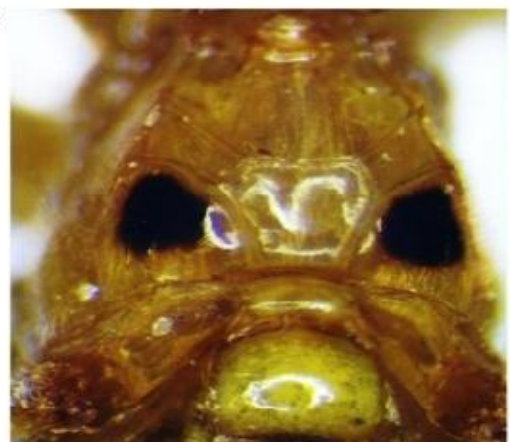

Figure 5. Propodium A. Xanthopimpla flavolineata B. Xanthopimpla punctate C. Xanthopimpla reicherti D. Xanthopimpla stremmator 

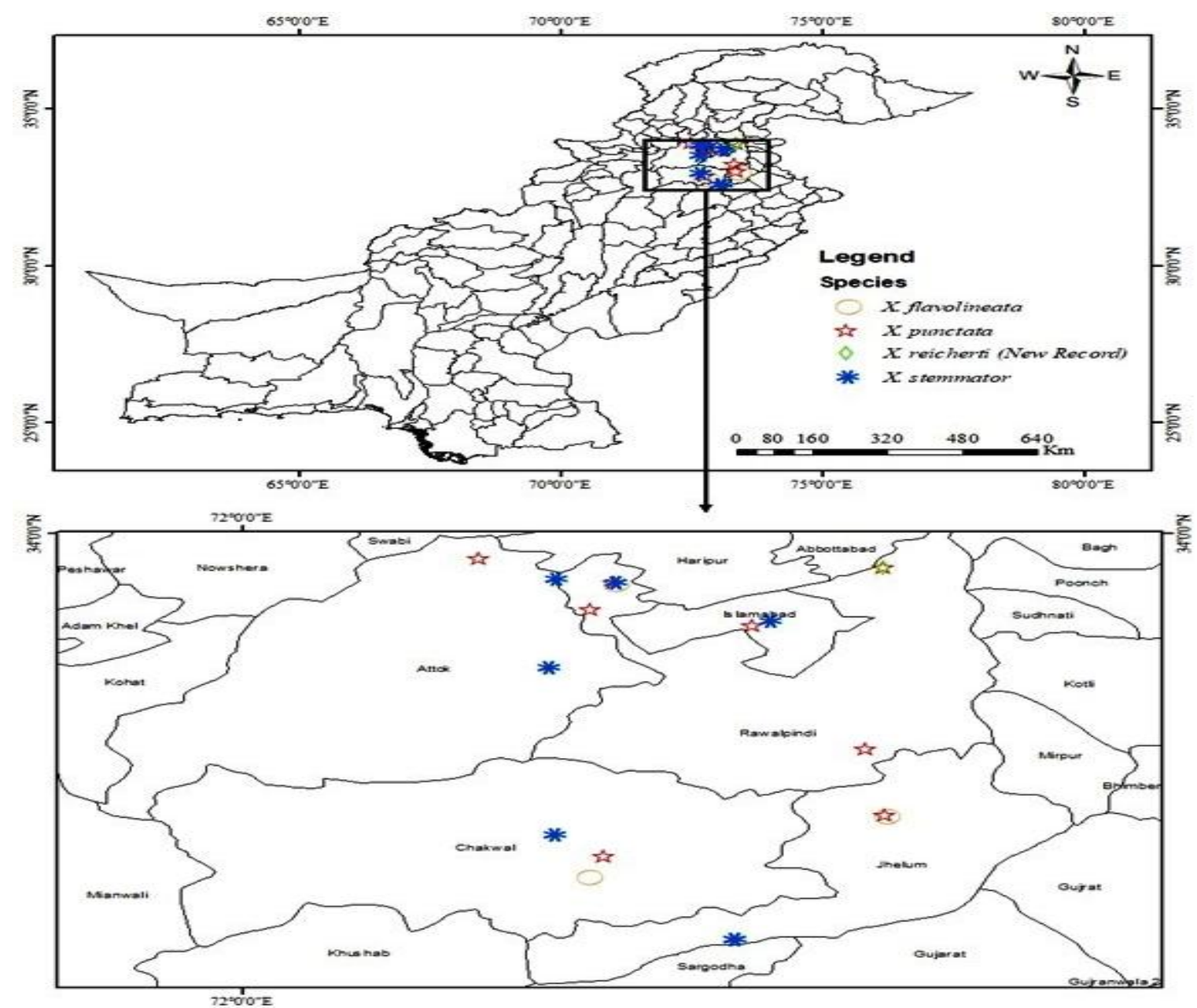

Figure 6. Distributional Map of Xanthopimpla species in Pothwar region Punjab Pakistan.

\section{DISCUSSION}

A total of 05 species belonging to five species groups have been reported from Pakistan, which are quite less in numbers as compared to recorded species of Xanthopimpla from neighboring countries; India 41 species, China 46 species, Nepal 12 species and 7 species from Sri-lanka (Akhtar et al., 2010). Asghar (2010) documented Xanthopimpla flavolineata from paddy area of Gujranwala, Sialkot and Skeikhupura. Whereas in this study Attock, Chakwal and Jehlum areas are new distributional range for this species (Fig .5). Xanthopimpla punctata was reported by Morely (1913) from Lahore as pupal parasitoid of Chilo suppressalis where as in this study species is reported from Attock, Rawalpindi and Islamabad. Xanthopimpla stemmator is reported first time from four district of Pothwar region earlier reported from different localities of Pakistan (Gupta, 1987).Genus Xanthopimpla is important parasitoid of stem bores of sugarcane, cereals and other crops. From Pakistan,Ghani (1960) reported Xanthopimpla punctata as a primary parasitoid of Sylepta derogata (Lepidoptera: Pyralidae) (cotton leaf roller). Xanthopimpla stemmator was also reported as parasitoid of Chilo partellus attacking maize crop from Pakistan (Carl, 1962; CIBC, 1973). This species was successfully utilized in biological control programme in Mauritius and Reunion Mozambique against Chilo partellus, Chilo sacchariphagus in sugarcane (Conlong and Goebel, 2002). Availability of indigenous parasitoids for biological control with correct taxonomic identification (Izfa and Idris, 2006) and knowledge of spatial and temporal distribution made it more successful for integrated pest control programme (David and Ghani, 2013). Prior to these studies no illustrations and keys were developed for these species of this genus. Now detailed illustrations given in these studies may help the researchers for probable utilization of these species in various districts of Pothwar region against various insects' pests of crops.

Acknowledgments: We are grateful to Centre for Agriculture and Bioscience International Pakistan and Mr. Naveed Ahmed Entomologist Pakistan Forest 
Institute, Peshawar for supporting in identification of species by comparing the specimen with Museum collection identified from Natural History Museum London. We are also thankful to Horticultural Research Institute for Floriculture \& Landscaping Rawalpindi, Punjab Forest Department, Syed Yousaf Shah, Farm Manager Saigol Farms Chakwal and Zeeshan Malik owner Zeeshan Farms Attock for cooperation in sampling from their premises.

\section{REFERENCES}

Akhtar, M. S., M. M. Kumawat, and V. V. Ramamurthy (2010). An annotated checklist of Xanthopimpla Saussure (Hymenoptera: Ichneumonidae). Oriental Insects. 44: 243-269.

Asghar, M. (2010). Biodiversity of insects associated with rice (Oryza sativa L.) crop agroecosystem in the Punjab, Pakistan. Ph.D. dissertation, Uni Agri Faisalabad. 235 p.

Brooks, R.W. and D. B. Wahl (1987). Biology and mature larva of Hemipimpla pulchripennis (Saussure) a parasite of Ropalidia (Hymenoptera: Ichneumonidae: Vespidae). J New-York Entom Soc. 95: 547-552.

Butani, D.K. (1972). Parasites and predators recorded on insect pests of sugarcane in India. Indian Sugar. 22: 17-32.

Carl, K.P. (1962). Gramineous moth borers in West Pakistan. Technical Bulletin CIBC. 2: 29-76.

CIBC. (1973). Research on bionomics, biology and control of maize stem borer and its enemies. Final Technical Report. Commonwealth Institute of Biological control, Pakistan Station. 45 p.

Conlong, D. E., R. Goebel (2002). Biological control of Chilo sacchariphagus (Lepidoptera: Crambidae) in Mozambique. Proceedings of the South African Sugarcane Technologists Conference. 76: $310-320$.

David, A.D., Y.F. Ng, and A.G. Idris (2013). Xanthopimpla nullusis (Hymenoptera: Ichneumonidae: Pimplinae), a new species from Malaysia. Serangga. 7(2): 1-12.

David, D. A., I. A. Ghani (2013). Description of Five Species of Xanthopimpla Saussure 1892 (Hymenoptera: Ichneumonidae: Pimplinae) from Malaysia. AIP Conference Proceedings. 1571. 349-354.

Dung, D.T., L.T. Phuong and K.D. Long (2011) Insect parasitoid composition on soybean, some ecobiological characteristics of the parasitoid, Xanthopimpla punctate (Fabricius) on soybean leaf folder Omiode sindicata (Fabricius) in Hanoi, Vietnam. J Inter Soc Southeast Asian Agri Sci. 17: 58-69.
Eady, R. D. (1968). Some illustrations of microsculpture in the Hymenoptera. Proc Royal Entomo Soc London Series A. 43:66-72

Facknath, S. (1989). Biological control of sugar-cane pests in Mauritius: A case study. Ins Sci App. 10: 809813.

Ganeshan S., A. Rajabalee (1997). Parasitoids of the sugarcane spotted borer, Chilo sacchariphagus (Lepidoptera: Pyralidae) in Mauritius. Proceedings of the Annual Congress South African Sugar Technologists Association. 71: 8790.

Ganeshan, S. (2000). Biological control of sugarcane pests in Mauritius: current status and future prospects, p. 3-9 in: Proceedings of the IV Sugarcane Entomology Workshop, ISSCT.

Gauld, I. D. (1984). An introduction to the Ichneumonidae of Australia, British Museum, London. 413 p.

Gauld, I.D. (1991). The Ichneumonidae of Costa Rica, 1. Mem Amer Entomo Inst. 47, 1-589.

Gauld, I.D., D.B. Wahl, and G. R. Broad (2002). The suprageneric groups of the Pimplinae (Hymenoptera: Ichneumonidae): a cladistic reevaluation and evolutionary biological study. Zoo J Linn Soc. 136: 21-485.

Ghani, M. A. (1960). Sylepta derogata and possibilities of its biological control in Pakistan. Commonwealth Agricultural Bureau, Slough. 42 p.

Gitau, C. W., A. J. Ngi-Song, S. A. Otieno, and W. A. Overholt (2007). Host preference of Xanthopimpla stemmator (Hymenoptera: Ichneumonidae) and its reproductive performance on selected African lepidopteran stem borers. Biocontrol Science and Technology. 17(5): 499511.

Gómez, I. C., I. E. Sääksjärvi, G.R. Broad, L. Puhakka, C. Peña, C Castillo and D. Padu (2014) The Neotropical species of Xanthopimpla Saussure (Hymenoptera, Ichneumonidae). Zootaxa. 3774 (1): 057-073.

Gómez, I.C., I. E. Sääksjärvi, A. Veijalainen, and G. R. Broad (2009). Two new species of Xanthopimpla (Hymenoptera, Ichneumonidae) from Western Amazonia, with a revised key to the Neotropical species of the genus. ZooKeys. 14: 55-65.

Gupta, V.K. (1987). The Ichneumonidae of the IndoAustralian area (Hymenoptera). Mem Amer Entomo Inst. 41(1): 1-597.

Hailemichael, Y, J.W. Smith, Jr. and R.N. Wiedenmann (1994). Host finding behavior, host acceptance, and host suitability of the parasite Xanthopimpla stemmator. Entomol. Expo. Appl. 71: 155-166.

Irshad, M. andM.R. Khan (2005). Insect pests of plants and their parasitoids, predators and pathogens in Pakistan. PIPS Ltd. 72 p. 
Izfa, R.H. and A. B Idris (2006). Xanthopimpla mardiensis, a new species of Pimplinae from Sarawak, Malaysia (Hymenoptera: Ichneumonidae). Serangga. 11(1-2):45-52.

Jonathan, J. K. (1999). Fauna of West Bengal-Part 8. Zool Surv India, Kolkata. 442 p.

Khuat, D. L. and T.N. Pham (2007). An inventory of parasitic Ichneumonoid wasps (Hymenoptera: Ichneumonoidea) reared from agricultural pest insects in Vietnam. Proceedings of the 2nd National Workshop on Ecology and Biological Resources.Agricultural Publishing House, Hanoi. 153-162.

Krieger, R. (1914) Ueber die Ichneumonidengattung Xanthopimpla Sauss. Archivfür Naturgeschichte. 80 (6): 1-148.

Matsumoto, R. and K. Konishi (2007). Life histories of two Ichneumonid parasitoids of Cyclosa octotuberculata (Araneae): Reclinervellus tuberculatus (Uchida) and its new sympatric congener (Hymenoptera: Ichneumonidae: Pimplinae). Entomo Sci. 10: 267-278.

Morley C. (1913). The Fauna of British India Including Ceylon and Burma, Hymenoptera, 3, Ichneumonidae. British Museum, London. 531 p.

Pham N. T. (2013). Taxonomy and distributional pattern of Pimplinae (Hymenoptera: Ichneumonidae) from Vietnam. Ph.D. dissertation, Uni Bonn. 285 p.

Pham, N.T., G.R. Broad, R. Matsumoto and W. Wägele (2011). Revision of the genus Xanthopimpla Saussure (Hymenoptera: Ichneumonidae:
Pimplinae) in Vietnam, with description of fourteen new species. Zootaxa. 3056: 1-67.

Saussure, H. D. (1892). Hymenopteres. In: Grandidier, A. (Ed.), Histoire physique naturelle et politique de Madagascar. 20, Paris. 590 p.

Seyrig, A. (1932). Les Ichneumonides de Madagascar. I Ichneumonidae Pimplinae. Memoires de l'Academie Malgache. 11: 1-183.

Thunberg, C. P. (1822). Ichneumonidea, Insecta Hymenoptera illustrata. Mémoires de l'Académie Imperiale des Sciences de Saint Petersbourg. 8: 249-281.

Tosquinet, J. (1896) Contributions la fauna entomologique de l'Afrique. Ichneumonides. Mémoires de la Sociét Entomologique de Belgique. 5: 1-430.

Townes H. K., M. Townes, V. K. Gupta (1961). A catalogue and reclassification of the IndoAustralian Ichneumonidae. Mem Amer Entomo Inst. 522 p.

Townes, H. K. (1969). The Neotropic species of Xanthopimpla (Hymenoptera: Ichneumonidae). Proceedings of the Entomological Society of Washington. 71: 82-88.

Townes, H.K. and S.C. Chiu (1970). The Indoo-Australian species of Xanthopimpla (Ichneumonidae). Mem Amer Entomo Inst. 14: 1-372.

$\mathrm{Yu}$, D.S., K. van Achterberg and K. Horstmann (2005). World Ichneumonoidea 2004. Taxonomy, Biology, Morphology and Distribution. DVD/CD. Taxapad, Vancouver, Canada. 